\title{
ИССЛЕДОВАНИЕ ЭФФЕКТИВНОСТИ ВЫНОСА ВОДЫ И МЕХАНИЧЕСКИХ ПРИМЕСЕЙ С ЗАБОЯ НЕФТЯНЫХ СКВАЖИН
}

\author{
Уразаков Камил Рахматуллович'1, \\ urazakk@mail.ru
}

\author{
Алиметов Шамиль Агаметович², \\ felix8047@mail.ru
}

Тугунов Павел Михайлович1, PavelTugunov@gmail.com

1 Уфимский государственный нефтяной технический университет, Россия, 450062, г. Уфра, ул. Космонавтов, 1.

2 «Когалымнестегаз», ООО «ЛУКОЙЛ - Западная Сибирь», Россия, 628486, г. Когалым, ул. Прибалтийская, 20.

\begin{abstract}
Актуальность. На сегодняшний день эксплуатация значительной доли нефтяных месторождений ведется механизированным способом и сопровождается рядом осложнений, обусловленных снижением дебита добывающих скважин, обводнением продукции, коррозией и отложением механических примесей в узлах насосного оборудования. Накопление пластовой воды и механических примесей в стволе скважин приводит к увеличению плотности смеси в скважине, снижению депрессии на пласт и дебита, повышению темпов коррозионного износа обсадной колонны. В этой связи одной из наиболее актуальных задач рентабельной эксплуатации скважин является обеспечение условий выноса пластовой воды и механических примесей из ствола скважин.

Объект: добывающие скважины, эксплуатирующие обводненные пласты, продукция которых содержит механические примеси. Интервал ниже приема насоса оборудован хвостовиком, предназначенным для увеличения скорости потока и обеспечения условий выноса пластовой воды и механических примесей.

Цель: обоснование оптимального диаметра хвостовика, обеспечивающего условия выноса пластовой воды и механических примесей с забоя скважин и соответственно минимальный перепад давления в стволе скважины ниже приема насоса.

Результаты. Исследовано влияние эксплуатационных параметров (обводненности, вязкости продукции, дебита) на фоормирование градиента давления в стволе скважины ниже приема насоса. Разработан расчетный метод определения диаметра хвостовика, обеспечивающего вынос воды и механических примесей с забоя обводненных нефотяных скважин, реализованный в виде компьютерной программы. Показано, что эфффективность использования хвостовика с точки зрения выноса пластовой воды увеличивается по мере снижения обводненности, вязкости продукции и дебита скважины. Установлено, что по мере снижения дебита скважины по жидкости диаметр хвостовика, необходимый для выноса механических примесей, уменьшается.
\end{abstract}

\section{Ключевые слова:}

Механистическая модель, хвостовик, вынос пластовой воды, механические примеси, градиент давления, обводненность, гидравлические потери.

\section{Введение}

Эксплуатация месторождений нефти и газа, в особенности на заключительном этапе разработки, ведется преимущественно механизированным способом и сопровождается рядом осложнений: снижение пластового давления и дебита добывающих скважин, обводнение продукции, отложение парафинов, неорганических солей, механических примесей в узлах внутрискважинного насосного оборудования [1, 2]. В частности, повышение обводненности продукции, обусловленное истощением залежей, закачкой пластовой воды в нагнетательные скважины для поддержания пластового давления в сочетании с низким дебитом приводит к накоплению пластовой воды в стволе скважин: обсадной колонне в интервале от приема насоса до забоя, нижнем конце колонны насосно-компрессорных труб, поскольку из-за разницы плотностей нефти и пластовой воды их относительная скорость возрастает. Накопление воды приводит к увеличению плотности смеси в стволе скважины и забойного давления, снижению депрессии на пласт и дебита. Контакт пластовой воды с поверхностью обсадной колонны приводит к ее повышенной коррозии. Для обеспечения той же величины дебита для обводненной скважины требуется более низкий уровень жидкости над насосом (за счет наличия тяжелого столба жидкости в интервале от приема до пласта), следовательно, снижается давление на приеме насоса, что, в свою очередь, ведет к снижению коэффициента подачи штангового насоса, напорной характеристики электроцентробежного насоса [3-5].

Таким образом, задача оптимизации условий выноса пластовой воды из ствола скважин является актуальной задачей, способствующей повышению рентабельности эксплуатации механизированного фонда. Для ее решения известны различные мероприятия и технические устройства, применяемые для увеличения скорости потока в трубах, ограничение притока воды из пласта, поступающей из подошвенной части, промывку скважин для очистки от песчаных пробок. Известны также технологии, включающие обработку призабойной зоны пласта поверхностно-активными веществами (ПАВ); 
применение труб с гладким внутренним полимерным покрытием, способствующим снижению потерь давления на гидравлические сопротивления, устранение источников обводнения скважинной продукции (негерметичности обсадной колонны и цементного кольца), изоляцию водоносных пластов [6, 7].

Одной из перспективных технологий, широко применяемой при эксплуатации газовых скважин, является оборудование скважины в интервале ниже приема насоса (штангового или электроцентробежного) хвостовиком, диаметр которого ниже диаметра обсадной колонны. При равном дебите скважины скорость потока в хвостовике выше, чем в обсадной колонне, в результате улучшаются условия выноса капель жидкости потоком газа (рис. 1). На сегодняшний день предложено два конструктивных варианта его исполнения: в первом случае хвостовик герметично соединяется с приемом насоса (рис. 1, a), во втором хвостовик устанавливается ниже приема насоса, причем межтрубное пространство (кольцевое пространство между хвостовиком и обсадной колон-

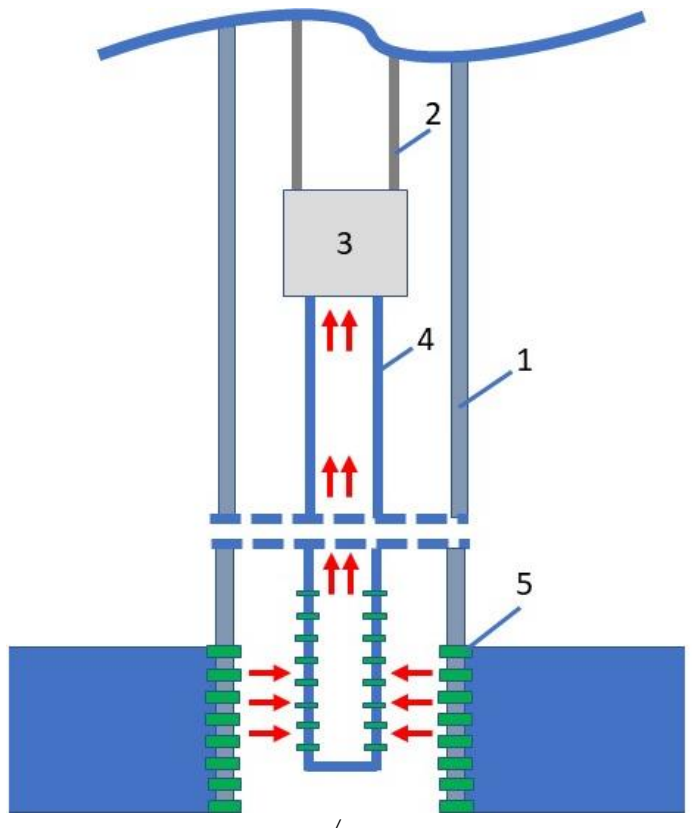

$a / a$ ной) изолируется в верхней части хвостовика пакером, и часть свободного газа на приеме насоса сепарируется в затрубное пространство (рис. 2, б). Преимуществом схемы, приведенной на рис. 2, б, является снижение объемной доли свободного газа на приеме насоса, что актуально при откачке продукции с высоким газовым фактором [8].

Несмотря на широкую распространенность данной технологии, в настоящее время нет общепринятых критериев обоснования оптимального диаметра трубы меньшего диаметра. С одной стороны, по мере снижения диаметра хвостовика увеличивается скорость восходящего потока и соответственно повышается эффективность выноса пластовой воды. С другой стороны, при увеличении скорости смеси в трубе возрастают и гидравлические потери давления на трение. Для обоснованного расчета оптимальных геометрических параметров хвостовика необходимо детальное исследование особенностей движения газожидкостного потока в скважине с учетом взаимовлияния приведенных факторов.

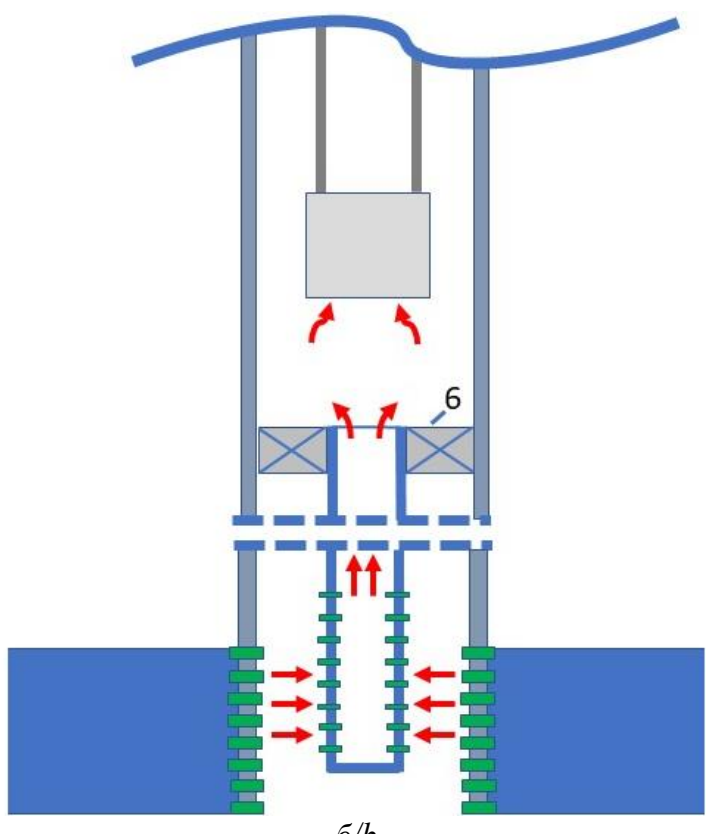

$6 / b$

Pис. 1. Конструкиия скважины с хвостовиком: а) соединение хвостовика с приемом насоса; б) хвостовик с пакером; 1 - обсадная колонна, 2 - насосно-компрессорные трубы, 3 - погружной насос, 4 -хвостовик, 5 - интервал перфорации продуктивного пласта, 6 - пакер, красным показано направление потоков в скважине

Fig. 1. Construction of a well with a shank: a) connection of the shank with the pump intake; $b$ ) shank with the packer; 1 casing, 2 -tubing, 3 submersible pump, 4 -shank, 5 - perforated interval of the reservoir, 6 -packer, the red shows the direction of the flow in the well

Известен ряд работ, посвященных исследованию движения многофазного газожидкостного потока в лифтовых/подъемных трубах и расчету перепада (градиента) давления в скважине с учетом наличия тяжелой фазы (жидкости, воды) в продукции скважины. Для расчета градиента давления по пути движения газожидкостной смеси широкое распространение получила зависимость

$$
\frac{1}{\rho_{l} g} \frac{d p}{d z}=\frac{\rho_{g}}{\rho_{l}}+\frac{\lambda}{2} F r^{*}+\Delta i,
$$

где $p$ - давление; $\rho_{g}, \rho_{l}-$ плотность газа и жидкости соответственно; $g$ - ускорение свободного падения; $\lambda$ - коэффициент трения; $F^{*}$ - модифицированный параметр Фруда; $\Delta i$ - дополнительный градиент давления, возникающий из-за наличия жидкости в потоке. В работах $[9,10]$ показано, что критерий Фруда является ключевым параметром газожидкостных потоков, определяющим, в частности, условия устойчивого выноса жидкости с забоя добывающих скважин. Для величины дополнительного градиента давления установлено, что он определяется, прежде всего, объ- 
емным расходом жидкости и диаметром подъемной трубы.

Вопросы расчета критических параметров потока, в частности критической скорости, обеспечивающей вынос пластовой жидкости потоком газа, рассмотрены в работе [11]. Расчетный метод основан на определении скорости газа, превышающей конечную скорость падения капель жидкости в газовой среде, равной:

$$
v_{c}=1,8949\left[\frac{\sigma\left(\rho_{l}-\rho_{g}\right)}{\rho_{g}{ }^{2}}\right]^{0,25},
$$

где $\sigma$ - поверхностное натяжение на границе газжидкость.

Следует отметить, что рассмотренные выше зависимости (1), (2) применимы главным образом для расчета параметров потока газовых скважин, продукция которых содержит в себе небольшое количество жидкости. Известны также экспериментальные исследования двухфазного течения смеси воды и керосина, проводимые для выявления закономерностей и условий выноса воды на поверхность при эксплуатации добывающих обводненных скважин [12]. Установлено, что полный вынос воды происходит при скоростях смеси, превышающих 0,12-0,15 м/с, причем критическая скорость выноса воды с забоя на поверхность близка к скорости оседания капель воды в жидкостном потоке. Так как реологические свойства нефти варьируются в зависимости от состава, пластового давления и температуры и отличаются от свойств керосина, данные значения могут быть использованы в качестве первого приближения для оценки критической скорости потока.

Исследование движения газонефтяного потока с учетом физико-химических свойств воды, нефти и газа для установления области рационального применения хвостовиков проведено в работе [13]. Рассмотрена задача определения критического дебита, при котором относительное движение компонентов не будет сказываться на величине удельного веса (плотности смеси) и условия движения многокомпонентного потока будут близки к идеальным. Показано, что удельный вес водонефтяной смеси $\rho_{f}$ с учетом относительного движения можно рассчитать согласно зависимости

$$
\begin{gathered}
\rho_{f}=\rho_{o}+\frac{\rho_{w}-\rho_{o}}{2}\left[1-\frac{1}{a n}+\sqrt{\left(1-\frac{1}{a n}\right)^{2}+\frac{4}{a}}\right], \\
n=\frac{Q_{w}}{Q_{w}+Q_{o}} ; a=\frac{f C_{s}}{Q_{w}},
\end{gathered}
$$

где $\rho_{w}, \rho_{o}-$ плотность воды и нефти соответственно; $n$ - относительное объемное содержание воды в смеси; $a$ - безразмерный коэффициент; $Q_{w}, Q_{o}-$ дебит воды и нефти соответственно; $f$ - площадь поперечного сечения лифтовых труб; $C_{s}-$ относительная скорость нефти и воды. Известно, что плотность смеси в идеальном случае равна

$$
\rho_{f}^{\prime}=\rho_{o}(1-n)+\rho_{w} n .
$$

Приравняв выражения (3), (4), можно получить формулу для расчета критического дебита, которая имеет вид

$$
\left.Q_{c r}=\frac{f C_{s}}{\left(\rho_{w}-\rho_{o}\right)\left(\frac{1-n}{\rho_{w}-k\left(\rho_{o}(1-n)+\rho_{w} n\right)}-\right.}\right),
$$

где $k$ - коэффициент, характеризующий степень отклонения плотности реальной смеси от идеальной. Обоснованный расчет коэффициента $k$ требует дополнительных промысловых замеров давления в скважине, что является недостатком зависимости (5).

Для расчета многофазных газожидкостных потоков с заданным объемным расходом нефти, воды и газа в потоке широко применяются эмпирические корреляции (H.D. Beggs \& J.P. Brill, H. Mukherjee \& J.P. Brill, H.Jr. Duns \& N.C.J. Ros и др.) и механистические модели (A.R. Hasan \& C.S. Kabir, A.M. Ansari, A. Petalaz \& K. Aziz и др.). Они позволяют учитывать эффекты проскальзывания (газа в жидкости, нефти и воде), режимы течения, причем наиболее точно характеристики потока прогнозируются с помощью механистических моделей, базирующихся на фундаментальных законах сохранения массы и импульса $[14,15]$. В данной работе для расчета параметров многофазного потока используется механистическая модель потока дрейфа («drift-flux»). Достоинством модели является учет взаимного перемещения (проскальзывания) фаз, что позволяет учесть физические эффекты, наблюдаемые при образовании водяных «стаканов» на забое или в нижнем конце НКТ добывающих скважин.

\section{Математическая модель}

Расчет многофазного течения газожидкостного потока в интервале от кровли продуктивного пласта до приема погружного насоса проводится в рамках модели «drift-flux» [16]. Согласно модели, объемная доля газа и нефти с учетом относительного движения газа в потоке жидкости и нефти в потоке воды определяется согласно зависимостям:

$$
\begin{gathered}
H_{g}=\frac{V_{s g}}{C_{g} V_{m}+V_{s l_{-} g}} ; \\
H_{o}=\frac{V_{s o}}{C_{o} V_{l}+V_{s l_{-} o}},
\end{gathered}
$$

где $H_{g}, H_{o}$ - истинная объемная доля газа и нефти соответственно; $V_{s g}, V_{s o}$ - приведенная скорость газа и нефти соответственно; $C_{g}, C_{o}-$ безразмерные поправочные коэффициенты, учитывающие неравномерность распределения пузырьков газа и капель нефти в потоке; $V_{m}, V_{l}-$ истинные скорости смеси и жидкости соответственно; $V_{s l_{-} g}, V_{s l_{-} o}-$ скорость дрейфа пузырьков газа в жидкости и капель нефти в воде, причем относительная скорость подъема нефти в потоке в формуле (6) рассчитывается как 


$$
\begin{aligned}
& V_{s l_{-} o}=1,53\left(1-H_{o}\right)^{2}(\cos \theta)^{0,5} \times \\
& \times(1+\sin \theta)^{2}\left(\frac{\sigma_{o w} g\left(\rho_{w}-\rho_{o}\right)}{\rho_{w}^{2}}\right)^{1 / 4},
\end{aligned}
$$

где $\sigma_{o w}-$ поверхностное натяжение на границе нефтьвода; $\theta$ - угол наклона оси скважины к вертикали.

Градиент давления в лифтовой трубе (обсадной колонне, хвостовике) определяется согласно формуле:

$$
\frac{d p}{d z}=f_{m} \frac{\rho_{m} V_{m}^{2}}{2 s}+\rho_{m} g \sin \alpha,
$$

где $f_{m}-$ коэффициент трения; $\rho_{m}-$ плотность многофазной смеси с учетом проскальзывания фаз; $s-$ гидравлический диаметр лифтовой трубы.

Одним из неблагоприятных факторов, осложняющих добычу нефти, является содержание в откачиваемой продукции взвешенных частиц механических примесей. Механические примеси являются одной из определяющих причин возникновения осложнений неисправностей в работе погружного оборудования $[1,3]$. Для расчета скорости подъема (оседания) взвешенных в потоке частиц записывается уравнение баланса сил [17-19]:

$$
\vec{F}_{g r}+\vec{F}_{a}+\vec{F}_{d}=0,
$$

где $F_{g r}, F_{a}, F_{d},-$ соответственно сила тяжести, выталкивающая (архимедова) сила, сила сопротивления со стороны жидкости:

$$
\begin{gathered}
\vec{F}_{g r}=\frac{1}{6} \pi d_{s}^{3} \rho_{s} \vec{g} ; \\
\vec{F}_{a}=\frac{1}{6} \pi d_{s}^{3} \rho_{m} \vec{g} ; \\
\vec{F}_{d}=\frac{1}{2} C_{d} \rho_{m} S_{s / g}\left(\vec{V}_{l}-\vec{V}_{s}\right)\left|\vec{V}_{l}-\vec{V}_{s}\right|,
\end{gathered}
$$

где $\rho_{s}, d_{s}-$ плотность и диаметр взвешенных частиц; $C_{d}$ - коэффициент сопротивления; $V_{l}, V_{s}$ - вектор скорости жидкости и механических примесей соответственно.

Оптимальный диаметр хвостовика рассчитывается на базе критерия обеспечения минимального результирующего перепада давления, складывающегося из двух составляющих - силы тяжести газонефтеводяной смеси, содержащей механические примеси, и гидравлических потерь на трение. При первоначальном снижении диаметра хвостовика относительно диаметра обсадной колонны перепад (градиент) давления снижается вследствие снижения плотности смеси благодаря увеличению скорости восходящего потока в хвостовике и обеспечению условий выноса пластовой воды. Однако при чрезмерном снижении диаметра хвостовика вследствие увеличения скорости потока возрастают гидравлические потери на трение, и перепад давления в скважине увеличивается. Нахождение оптимума (минимума) кривой зависимости градиента давления от диаметра хвостовика позволяет обеспечить минимальный перепад давления в обсадной колонне и максимизировать депрессию на пласт и дебит скважины. Расчетный диаметр хвостовика, при котором достигается минимум перепада давления, определяется из решения уравнения, получаемого приравниванием к нулю производной градиента давления (7) по диаметру хвостовика $s$ :

$$
s: \frac{d\left(f_{m} \frac{\rho_{m} V_{m}^{2}}{2 s}+\rho_{m} g \sin \alpha\right)}{d s}=0,
$$

Изложенный метод реализован в виде компьютерной программой для расчета оптимального диаметра хвостовика, обеспечивающего вынос воды и механических примесей (8) с забоя добывающих обводненных скважин, с учетом конкретных условий эксплуатации.

\section{Анализ результатов расчетов}

Построены зависимости перепада давления в обсадной колонне ниже приема насоса (разницы между забойным давлением и давлением на приеме) от диаметра используемого хвостовика, и исследовано влияние эксплуатационных параметров (обводненности, вязкости продукции, дебита) на эффективность выноса пластовой воды. Правая граница диаметра хвостовика соответствует внутреннему диаметру обсадной колонны. В таблице приведена геометрия скважины и реологические свойства откачиваемой продукции, принятые при моделировании. В расчетном примере в первом приближении моделируется водонефтяной

\begin{tabular}{|c|c|}
\hline Глубина спуска насоса, м/Pump descent depth, m & 1000 \\
\hline Глубина кровли пласта, м/Reservoir roof depth, m & 1200 \\
\hline $\begin{array}{l}\text { Внутренний диаметр обсадной колонны, мм } \\
\text { Inner diameter of the casing string, mm }\end{array}$ & 130 \\
\hline 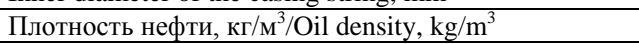 & 800 \\
\hline Плотность воды, кг $/ \mathrm{M}^{3} /$ Water density, $\mathrm{kg} / \mathrm{m}^{3}$ & 1100 \\
\hline Обводненность/Water cut, \% & $10-90$ \\
\hline $\begin{array}{l}\text { Плотность частиц механических примесей, кг } / \mathrm{M}^{3} \\
\text { Density of particle of mechanical impurities, } \mathrm{kg} / \mathrm{m}^{3}\end{array}$ & 1500 \\
\hline $\begin{array}{l}\text { Диаметр частиц механических примесей, мкм } \\
\text { Diameter of particles of mechanical impurities, microns }\end{array}$ & $1-500$ \\
\hline $\begin{array}{l}\text { Коэффициент продуктивности пласта, м³/(сут·МПа) } \\
\text { Reservoir performance coefficient, } \mathrm{m}^{3} /(\text { day·MPa) }\end{array}$ & 10 \\
\hline Пластовое давление, МПа/Reservoir pressure, MPa & 12 \\
\hline Дебит жидкости, $\mathrm{m}^{3} /$ сут./Liquid flow rate, $\mathrm{m}^{3} /$ day & $50-150$ \\
\hline Давление на приеме, МПа/Intake pressure, MPa & 5 \\
\hline Вязкость воды, мПа·с/Water viscosity, MPa·s & 1 \\
\hline Вязкость нефти, мПа·c/Oil viscosity, MPa·s & $2-30$ \\
\hline Поверхностное натяжение, H/м/Surface tension, & 0,05 \\
\hline
\end{tabular}
поток без учета влияния газа. Двухфазный поток нефти и воды реализуется в скважине в интервале ниже приема насоса при следующих условиях: давление на приеме превышает давление насыщения, небольшой газовый фактор нефти.

Таблица. Исходные данные

Table. Initial data

Следует отметить, что наличие газа в продукции улучшает условия выноса пластовой воды: вопервых, поток выделяющегося из нефти и расширяющегося газа по мере подъема скважиной продукции способствует выносу пластовой воды, как и для газовых скважин; во-вторых, при разгазировании нефти 
ее плотность и вязкость несколько возрастают, что приводит к снижению относительной скорости движения фаз (воды и нефти). Таким образом, расчетные значения оптимального диаметра хвостовика, полученные для условий двухфазного водонефтяного потока, могут рассматриваться как оценка «сверху», обеспечивающая условия выноса пластовой воды совместными потоками нефти и газа в трехфазном потоке.

С увеличением обводненности эффективность использования хвостовика закономерно снижается (рис. 2), поскольку пластовая вода непрерывно поступает в скважину из пласта, исключая ее полный вынос. При небольшой обводненности (10 \%) использование хвостовика позволяет снизить противодавление на пласт на величину порядка 0,25 МПа, что соответствует увеличению дебита скважины по жидкости и нефти соответственно до $2,5 \mathrm{~m}^{3} /$ сут и 1,8 т/сут $(5 \%)$.

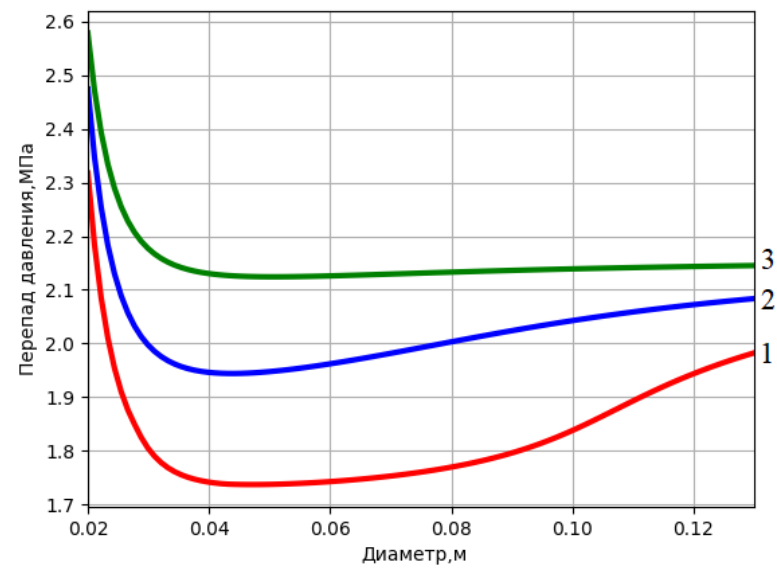

Pис. 2. Зависимость перепада давления в хвостовике от его диаметра, обводненности: $1-10 \%, 2-50 \%$, $3-90 \%$

Fig. 2. Dependence of the pressure drop in the shank on its diameter, water content: $1-10 \%, 2-50 \%, 3-90 \%$

С увеличением дебита скважины по жидкости эффективность использования хвостовика снижается (рис. 3), поскольку с ростом дебита улучшаются условия выноса пластовой воды и в обсадной колонне. Оптимальное значение диаметра хвостовика увеличивается с ростом дебита, в частности, при увеличении дебита с 50 до $150 \mathrm{~m}$ /сут. оптимальный диаметр хвостовика, обеспечивающий вынос пластовой воды, возрастает с 45 до 70 мм (на 55 \%). Снижение эффективности хвостовика при увеличении вязкости нефти обусловлено ростом гидравлических потерь на трение при снижении его диаметра (рис. 4). При увеличении вязкости нефти от 2 до 30 мПағс оптимальное значение диаметра хвостовика возрастает с 43 до 48 мм (на $12 \%$ ).

Следует отметить, что при работе скважины без хвостовика происходит процесс всплытия нефтяной фазы через столб пластовой воды, который накапливается на забое скважины, снижая депрессию на пласт. Оборудование скважины хвостовиком позволяет снизить относительную скорость фаз и создать условия выноса пластовой воды вместе с нефтью. Известно [8], что критическая скорость нефти, необходимая для выноса стоячей жидкости всплывающим потоком нефти, в несколько раз меньше критической скорости, обеспечивающей вынос пластовой воды при совместном движении нефтяной и водяной фаз. Рассчитанный по предложенному методу диаметр хвостовика обеспечивает скорость нефтяной фазы, достаточную для выноса движущейся воды в откачиваемой продукции, следовательно, обеспечивает и вынос стоячей воды с забоя скважины.

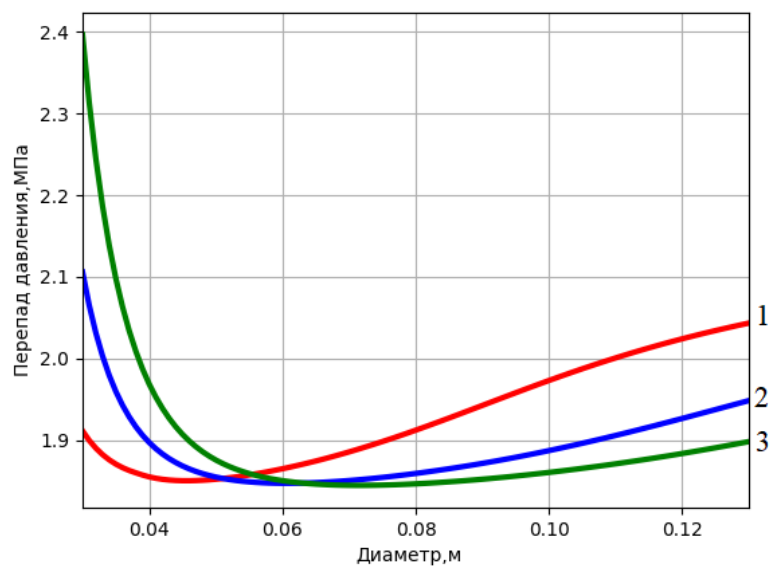

Pис. 3. Зависимость перепада давления в хвостовике от его диаметра, дебитьл: $1-50 \mathrm{~m}^{3} / \mathrm{cym} ., 2-100 \mathrm{~m}^{3} /$ суm., $3-150 \mathrm{M}^{3} / \mathrm{cym}$.

Fig. 3. Dependence of the pressure drop in the shank on its diameter, flow rates: $1-50 \mathrm{~m}^{3} /$ day, $2-100 \mathrm{~m}^{3} /$ day, $3-150 \mathrm{~m}^{3} / \mathrm{day}$

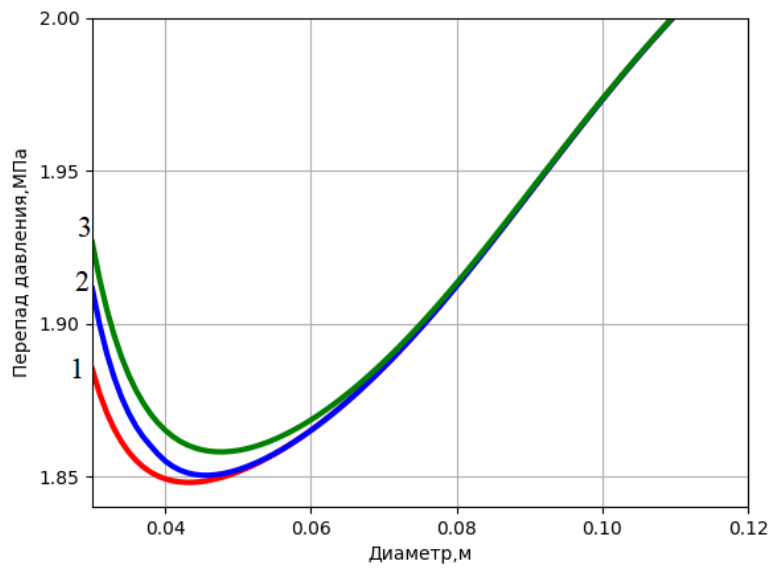

Pис. 4. Зависимость перепада давления в хвостовике от его диаметра, вязкость нефти: 1 - 2 мПа·с, 2 $10 \mathrm{M \Pi a} \cdot \mathrm{c}, 3-30 \mathrm{M \Pi a} \cdot \mathrm{c}$

Fig. 4. Dependence of the pressure drop in the shank on its diameter, oil viscosity: $1-2 \mathrm{mPa} \cdot \mathrm{s}, 2-10 \mathrm{mPa} \cdot \mathrm{s}$, $3-30 \mathrm{mPa} \cdot \mathrm{s}$

На графиках (рис. 5) показана величина минимального дебита скважины, требуемого для подъема частиц механических примесей заданного диаметра в обсадной колонне внутренним диаметром 130 мм, обводненность жидкости принята $30 \%$. Из графиков видно, что для скважин, эксплуатируемых установками электроцентробежных насосов (УЭЦН), дебит ко- 
торых, как правило, превышает 30-40 м³/сут., механические примеси, размер которых колеблется в интервале 1-250 мкм, будут подниматься вместе с потоком. При откачке нефти вязкостью 2 мПа॰с для подъема крупных частиц механических примесей диаметром 400-500 дебит скважины по жидкости должен превышать $60 \mathrm{~m}^{3} /$ сут, в противном случае возможно образование застойных зон в интервале ниже приема насоса с повышенной концентрацией механических примесей, накапливающихся вследствие недостаточной скорости потока. Для исключения этого явления рационально оборудовать интервал от приема насоса до забоя хвостовиком.

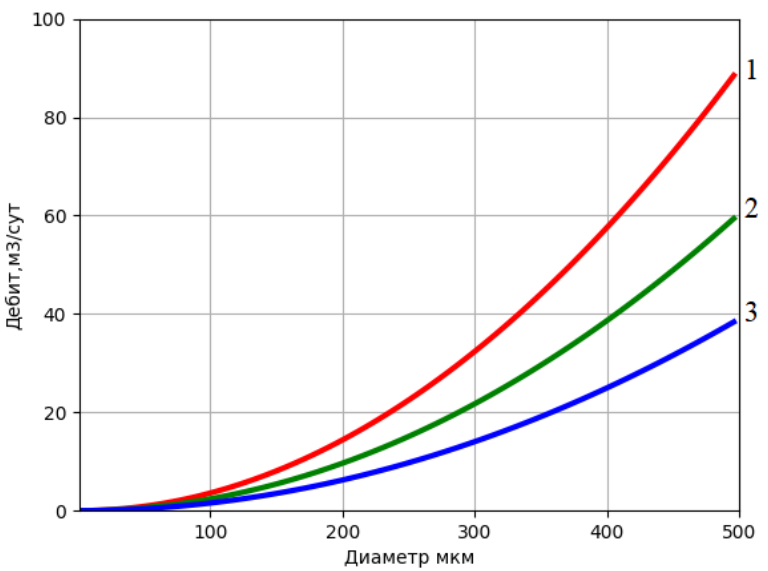

Pис. 5. Минимальный дебит скважины, требуемый для подъема частии механических примесей заданного диаметра (вязкость нефти: 1 - 2 мПасс, 2 -

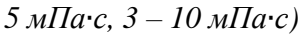

Fig. 5. Minimum well flow rate required for lifting particles of mechanical impurities of a given diameter (oil viscosity: $1-2 \mathrm{mPa} \cdot \mathrm{s}, 2-5 \mathrm{mPa} \cdot \mathrm{s}, 3-10 \mathrm{mPa} \cdot \mathrm{s}$ )

Полагая, что коэффициент сопротивления потока движению механических примесей $C_{d}$ подчиняется закону Стокса [20], можно получить следующее выражение для расчета диаметра хвостовика, обеспечивающего вынос механических примесей размером $d_{s}$ :

$$
s=\sqrt{\frac{72 Q_{m} \mu_{m}}{\pi g\left(\rho_{s}-\rho_{m}\right) d_{s}^{2}}},
$$

где $\mu_{m}-$ вязкость смеси; $Q_{m}-$ дебит жидкости. На графиках (рис. 6) показаны результаты расчета диаметра хвостовика по формуле (9) при различном дебите жидкости (при моделировании принято $\mu_{m}=2$ мПа с, $\left.\rho_{m}=1050 \mathrm{\kappa} \Gamma / \mathrm{M}^{3}\right)$.

С увеличением дебита жидкости интенсивность выноса механических примесей увеличивается, в частности, при дебите $80 \mathrm{~m} /$ сут. и более осуществляется вынос практически всех фракций механических примесей (диаметром до 470 мкм) даже в обсадной колонне. При дебите $60 \mathrm{~m}^{3} /$ сут. использование хвостовика диаметром 106 мм позволяет исключить

\section{СПИСОК ЛИТЕРАТУРЫ}

1. Справочник по добыче нефти / К.Р. Уразаков, Э.О. Тимашев, В.А. Молчанова, М.Г. Волков. - Пермь: Астер Плюс, 2020. $600 \mathrm{c}$. накопление на забое и обеспечить вынос наиболее крупных частиц (диаметром до 500 мкм), при дебите $40 \mathrm{~m}^{3} /$ сут. расчетный диаметр хвостовика составляет 87 мм. Таким образом, по мере снижения дебита скважины необходимый для выноса механических примесей диаметр хвостовика также уменьшается.

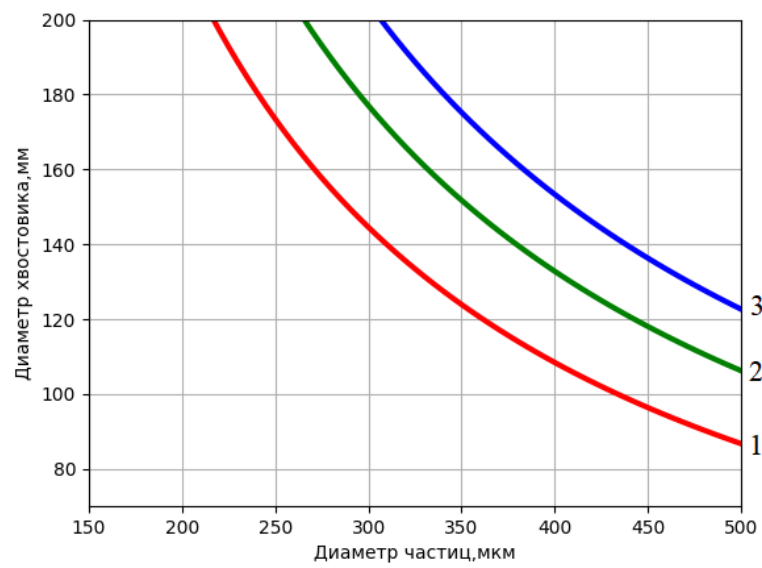

Pис. 6. Диаметр хвостовика, требуемый для подъема частии механических примесей заданного диаметра (дебит по жидкости: 1 - $40 \mathrm{~m}^{3} /$ сут., 2 $60 \mathrm{~m}^{3} /$ cym., $3-80 \mathrm{M}^{3} /$ cym.)

Fig. 6. Shank diameter required for lifting particles of mechanical impurities of a given diameter (flow rate: $1-40 \mathrm{~m}^{3} /$ day, $2-60 \mathrm{~m}^{3} /$ day, $3-80 \mathrm{~m}^{3} /$ day)

\section{Выводы}

1. Разработан и обоснован метод расчета диаметра хвостовика, спускаемого в скважину ниже приема погружного насоса, обеспечивающего вынос воды и механических примесей с забоя обводненных нефтяных скважин. Метод расчета оптимального диаметра хвостовика, учитывающий конкретные скважинные условия, реализован в виде компьютерной программы.

2. Проанализировано влияние эксплуатационных параметров (обводненности, вязкости продукции, дебита) на эффективность выноса пластовой воды. Показано, что эффективность использования хвостовика увеличивается по мере снижения обводненности, вязкости продукции и дебита скважины, причем при оптимальном диаметре хвостовика достигается увеличение дебита скважины по жидкости и нефти до $5 \%$.

3. Исследованы особенности выноса механических примесей с забоя скважин: установлено, что при дебитах более $80 \mathrm{~m}^{3} /$ сут. осуществляется вынос механических примесей практически всех фракций (размером до 470 мкм) в обсадной колонне (диаметром 130 мм). По мере снижения дебита до 40 м³/сут. необходимый для выноса механических примесей диаметр хвостовика уменьшается до 87 мм.

2. Диагностирование технического состояния электроцентробежных насосных установок по уровню их вибрации / К.Р. Уразаков, Е.Б. Думлер, А.С. Топольников, Р.И. Вахитова // Нефтегазовое дело. - 2017. - Т. 15. - № 1. - С. 103-107. 
3. Takacs G. Electrical submersible pumps manual. - Houston, Texas: Gulf Professional Publ., 2017. - 578 p.

4. Уразаков К.Р., Тимашев Э.О., Молчанова В.А. Моделирование работы погружных плунжерных насосных установок с пневмокомпенсаторами // Известия Томского политехнического университета. Инжиниринг георесурсов. - 2020. T. 331. - № 12. - C. 51-59.

5. Тимашев Э.О., Уразаков К.Р. Гидродинамика газожидкостного потока в насосных трубах штанговых установок // Нефтегазовое дело. - 2020. - Т. 18. - № 4. - С. 125-133.

6. Якупов Р.Р., Яркеева Н.Р. Оптимизация работы газовых скважин на Ямбургском нефтегазоконденсатном месторождении // Нефтегазовое дело. - 2018. - Т. 16. - № 3. - С. 41-49.

7. Исследование температурного поля в скважине с индукционным нагревом колонны при наличии каналов заколонного перетока жидкости / Р.А. Валиуллин, Р.Ф. Шарафутдинов, В.Я. Федотов, Д.В. Космылин, И.В. Канафин // Вестник Тюменского государственного университета. Физикоматематическое моделирование. Нефть, газ, энергетика. 2017. - T. 3. - № 3. - C. 17-28.

8. Мищенко И.Т. Скважинная добыча нефти. - М.: ИЦ РГУ нефти и газа им. И.М. Губкина, 2015. - 448 c.

9. Николаев О.В., Соколов В.А. Методика расчета технологических параметров вертикальных газовых скважин, продукция которых содержит жидкость // Вести газовой науки. - 2016. № 2 (26). - С. 84-90.

10. Полуэмпирическая модель для расчета потерь давления в стволе вертикальной газовой скважины, работающей с выносом жидкости / В.А. Соколов, О.В. Николаев, И.В. Стоноженко, А.Г. Банникова // Вести газовой науки. - 2018. - № 1 (33). C. $151-158$.

11. Guidelines for the proper application of critical velocity calculations / R.P. Sutton, S.A. Cox, J.F. Lea, O.L. Rowlan // Society of Petroleum Engineers. - 2010. - V. 25. - № 2. - P. 182-194.
12. Технология механизированной добычи нефти / Н.Н. Репин, В.В. Девликамов, О.М. Юсупов, А.И. Дьячук. - М.: Недра, 1976. $-176 \mathrm{c}$

13. Эксплуатация глубинно-насосных скважин / Н.Н. Репин, В.Р. Еникеев, О.М. Юсупов, Ю.Г. Валишин, А.В. МарковОсоргин. - М.: Недра, 1971. - 168 с

14. Brill J.P., Mukherjee H.K. Multiphase flow in wells. - Richardson, Texas: SPE, 1999. - $164 \mathrm{p}$.

15. Petalas N., Aziz K. A mechanistic model for multiphase flow in pipes // Petroleum Society of Canada. - 1998. - № 1. - P. 1-22.

16. Drift-flux parameters for threephase steady-state flow in wellbores / H. Shi, J. Holmes, L. Diaz, L.J. Durlofsky, K. Aziz // SPE Journal. - 2005. - V. 10. - № 2. - P. 130-137.

17. Yang Y., Peng H., Wen Ch. Sand transport and deposition behaviour in subsea pipelines for flow assurance // Energies. 2019. - V. 21. - № 12. - P. 1-12.

18. On the numerical simulation of sand transport in liquid and multiphase pipelines / M. Leporinia, A. Terenzi, B. Marchetti, F. Corvaro, F. Polonara // Journal of Petroleum Science and Engineering. - 2019. - V. 175. - P. 519-535.

19. Viscosity effects on sand flow regimes and transport velocity in horizontal pipelines / E. Zorgani, H. Al-Awadi, W. Yan, S. AlLababid, H. Yeung, C.P. Fairhurst // Experimental Thermal and Fluid Science. - 2018. - V. 92. - P. 89-96.

20. Лугуманов Т.Т., Кулешов В.С. К моделированию динамики системы флюид - дисперсная среда // Труды Института механики имени Р.P. Мавлютова Уфимского Научного центра Российской Академии Наук. - 2014. - № 10. - С. 66-72.

Поступила 12.02.2021 г.

\section{Информация об авторах}

Уразаков К.P., доктор технических наук, профессор, профессор кафедры машин и оборудования нефтегазовых промыслов Уфимского государственного нефтяного технического университета.

Алиметов Ш.А., инженер-технолог, «Когалымнефтегаз», ООО «ЛУКОЙЛ - Западная Сибирь».

Тугунов П.М., ассистент кафедры машин и оборудования нефтегазовых промыслов Уфимского государственного нефтяного технического университета. 
UDC 622.279

\title{
INVESTIGATION OF THE EFFICIENCY OF REMOVING WATER AND MECHANICAL IMPURITIES FROM THE BOTTOM OF OIL WELLS
}

\author{
Kamil R. Urazakov 1 , \\ Urazakk@mail.ru \\ Shamil A. Alimetov², \\ felix8047@mail.ru \\ Pavel M. Tugunov'1, \\ PavelTugunov@gmail.com \\ 1 Ufa State Petroleum Technological University, \\ 1, Kosmonavtov street, Ufa, 450062, Russia. \\ 2 «Kogalymneftegaz», «LUKOIL - Western Siberia» LLC, \\ 20, Pribaltiyskaya street, Kogalym, 628486, Russia.
}

Relevance. To date, the exploitation of a significant share of oil fields is mechanized and is accompanied by a number of complications due to the decline in production rate wells, irrigation products, corrosion, and deposition of mechanical impurities in the components of the pumping equipment. The accumulation of reservoir water and mechanical impurities in the wellbore leads to the increase in the mixture density in the well, decrease in reservoir depression and flow rate, and growth in the rate of casing corrosion wear. In this regard, one of the most urgent tasks of cost-effective well operation is to ensure the conditions for removal of reservoir water and mechanical impurities from the well bore.

Object: producing wells that exploit watered formations, the products of which contain mechanical impurities. The interval below the pump intake is equipped with a shank designed to increase the flow rate and provide conditions for removal of reservoir water and mechanical impurities.

The purpose of the research is to substantiate the optimal diameter of the shank, which provides conditions for removal of reservoir water and mechanical impurities from the bottom of wells and, accordingly, the minimum pressure drop in the wellbore below the pump intake. Results. The influence of operational parameters (water cut, product viscosity, flow rate) on the formation of a pressure gradient in the wellbore below the pump intake is studied. The authors have developed a computational method for determining the diameter of the shank which ensures the removal of water and mechanical impurities from the bottom of waterlogged oil wells, implemented in the form of a computer program. It is shown that the efficiency of the shank use in terms of reservoir water removal increases as the water cut, the viscosity of the product and the flow rate of the well decrease. It is found that as the well flow rate decreases in the liquid, the diameter of the shank, which is necessary for removal of mechanical impurities, decreases.

\section{Key words:}

Mechanical model, shank, reservoir water removal, mechanical impurities, pressure gradient, water cut, hydraulic losses.

\section{REFERENCES}

1. Urazakov K.R., Timashev E.O., Molchanova V.A., Volkov M.G. Spravochnik po dobyche nefti [Handbook on oil extraction]. Perm, Aster Plyus Publ., 2020. 600 p.

2. Urazakov K.R., Dumler E.B., Topolnikov A.S., Vakhitova R.I Diagnostics of the technical condition of electric center-bearing pumping units by the level of their vibration. Petroleum Engineering, 2017, vol. 15, no. 1, pp. 103-107. In Rus.

3. Takacs G. Electrical submersible pumps manual. Houston, Texas, Gulf Professional Publishing, 2017. 578 p.

4. Urazakov K.R., Timashev E.O., Molchanova V.A. Simulation of operation of downhole plunger pumping installations with pneumatic compensators. Bulletin of the Tomsk Polytechnic University. Geo Assets Engineering, 2020, vol. 331, no. 12, pp. 51-59. In Rus.

5. Timashev E.O., Urazakov K.R. Hydrodynamics of gas-liquid flow in the tubing of rod pump installations. Petroleum Engineering, 2020, vol. 18, no. 4, pp. 125-133. In Rus.

6. Yakupov R.R., Yarkeeva N.R. Optimization of gas wells operation at the Yamburg gas field. Petroleum Engineering, 2018, vol. 16, no. 3, pp. 41-49. In Rus.

7. Valiullin R.A., Sharafutdinov R.F., Fedotov V.Ya., Kosmylin D.V., Kanafin I.V. Study of the temperature field in a well with induction heating of the column in the presence of channels of the back-water flow of liquid. Bulletin of the Tyumen State University. Physical and mathematical modeling. Oil, gas, and energy, 2017, vol. 3, no. 3, pp. 17-28. In Rus.
8. Mishchenko I.T. Skvazhinnaya dobycha nefti [Borehole oil production]. Moscow, Gubkin Russian State University of Oil and Gas Publ. Center, 2015. 448 p.

9. Nikolaev O.V., Sokolov V.A. Methodology for calculating the technological parameters of vertical gas wells, the products of which contain liquid. News of gas science, 2016, no. 2, pp. 84-90. In Rus.

10. Sokolov V.A., Nikolaev O.V., Stonozhenko I.V., Bannikova A.G. Semi-empirical model for calculating pressure losses in the trunk of a vertical gas well operating with liquid removal. News of gas science, 2018, vol. 33, no. 1, pp. 151-158.

11. Sutton R.P., Cox S.A., Lea J.F., Rowlan O.L. Guidelines for the proper application of critical velocity calculations. Society of Petroleum Engineers, 2010, vol. 25, no. 2, pp. 182-194.

12. Repin N.N., Devlikamov V.V., Yusupov O.M., Dyachuk A.I. tekhnologiya mekhanizirovannoy dobychi nefti [Technology of mechanized oil production]. Moscow, Nedra Publ., 1976. 176 p.

13. Repin N.N., Enikeev V.R., Yusupov O.M., Valishin Yu.G., Markov-Osorgin A.V. Ekspluatatsiya glubinno-nasosnykh skvazhin [Exploitation of deep-pump wells]. Moscow, Nedra Publ., 1971. $168 \mathrm{p}$

14. Brill J.P., Mukherjee H.K. Multiphase flow in wells. Richardson, Texas, SPE, 1999. $164 \mathrm{p}$.

15. Petalas N., Aziz K. A mechanistic model for multiphase flow in pipes. Petroleum Society of Canada, 1998, no. 1, pp. 1-22.

16. Shi H., Holmes J., Diaz L., Durlofsky L.J., Aziz K. Drift-flux parameters for threephase steady-state flow in wellbores. SPE Journal, 2005, vol. 10, no. 2, pp. 130-137. 
17. Yang Y., Peng H., Wen Ch. Sand transport and deposition behaviour in subsea pipelines for flow assurance. Energies, 2019, vol. 21 , no. 12 , pp. $1-12$.

18. Leporinia M., Terenzi A., Marchetti B., Corvaro F., Polonara F. On the numerical simulation of sand transport in liquid and multiphase pipelines. Journal of Petroleum Science and Engineering, 2019, vol. 175, pp. 519-535.

19. Zorgani E., Al-Awadi H., Yan W., Al-Lababid S., Yeung H., Fairhurst C.P. Viscosity effects on sand flow regimes and transport velocity in horizontal pipelines. Experimental Thermal and Fluid Science, 2018, vol. 92, pp. 89-96.

20. Lugumanov T.T., Kuleshov V.S. On modeling the dynamics of the fluid - dispersed medium system]. Proceedings of the R.R. Mavlyutov Institute of mechanics of the Ufa Scientific center of the Russian Academy of Sciences, 2014, no. 10, pp. 66-72. In Rus.

\section{Information about the authors}

Kamil R. Urazakov, Dr. Sc., professor, Ufa State Petroleum Technological University.

Shamil A. Alimetov, process engineer, TPP «Kogalymneftegaz», «LUKOIL - Western Siberia» LLC.

Pavel M. Tugunov, assistant, Ufa State Petroleum Technological University. 